\title{
An analysis of the subsurface fault systems with audio-magnetotelluric surveys in the western Ilan Plain of NE Taiwan
}

\author{
Ping-Yu Chang ${ }^{1,2, *}$, Gong-Rei Ho ${ }^{1}$, Chien-Chih Chen ${ }^{1}$, Han-Lun Hsu ${ }^{1}$, Chow-Son Chen ${ }^{1}$, and \\ En-Chao $\mathrm{Yeh}^{3}$ \\ ${ }^{1}$ Department of Earth Sciences, National Central University, Taoyuan City, Taiwan \\ ${ }^{2}$ Earthquake-Disaster \& Risk Evaluation and Management Center, National Central University, Taoyuan City, Taiwan \\ ${ }^{3}$ Department of Earth Sciences, National Taiwan Normal University, Taipei City, Taiwan
}

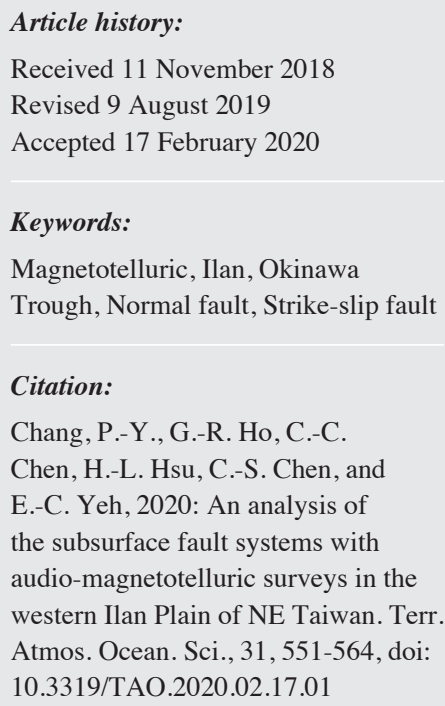

\begin{abstract}
We used the audio magnetotelluric (AMT) method to delineate subsurface resistivity structures associated with the western Ilan Plain, which is emerged from the orogenic belt in northeastern Taiwan and is thought to be influenced by the opening Okinawa Trough. The most recent extension phase of the Okinawa Trough starting from approximately 0.1 Ma involved ENE- and WSW-trending normal faults off the Ilan Plain. Nevertheless, the region was originally a thrust-and-fold belt related to the subduction of the Philippine Sea Plate under the Eurasia Plate. Our study focuses on how the later opening of the Okinawa Trough has affected this previously compressional region. From the results of the AMT surveys, we found that the area features a series of N-S trending fracture zones in addition to the E-W normal fault systems. Comparing the AMT data with the data from seismic reflection profiles, we found that the normal fault systems are truncated by young strike-slip faults and modified the relief of the rock basement in a recent stage of formation. The western part of the study area is dominated by left-lateral strike-slip faults while the eastern part is dominated by right-lateral strike-slip faults. The findings drawn from our AMT resistivity images as well as from the reinterpreted seismic profiles constitute new evidence that the extrusion regime may have gradually taken over the regional stress state and reset the regional stress-strain conditions that was one dominated by the Okinawa extension in the western and southern part of the Ilan plain.
\end{abstract}

\section{INTRODUCTION}

The Ilan Plain is located in northeastern Taiwan, and is thought to be an extension of the Okinawa Trough's back-arc basin within the Eurasian continental lithosphere (Ho 1986; Lai et al. 2009) (Fig. 1). Previous studies have shown that the recent phase of the Okinawa Trough extension started at approximately 0.1 Ma (Sibuet et al. 1998), and that extension involves activities of ENE- and WSWtrending normal faults dipping toward the Okinawa Trough axis with offsets ranging in length from a few meters to tens of meters (Sibuet et al. 1998; Lai et al. 2009) in the westernmost part of the trough off the Ilan Plain. By contrast, the Hsuehshan Range and the Central Ranges consisting of thrust-and-fold outcrops are located at the northern

\footnotetext{
* Corresponding author

E-mail:pingyuc@gmail.com
}

and southern part of the plain, and are part of the paleoorogenic belt. Therefore, the once compressional thrustand-fold belt of the Hsuehshan Range and the Central Range likely transitions into the region extending from the Okinawa Trough in the western Ilan Plain. Previous studies from regional geodetic measurements (shown in Fig. 1) and seismological analyses suggested that the surface deformation pattern of the southern part of the Ilan Plain and the northern Central mountain are rotating clockwise while the Hsueshan mountain and the northern Ilan Plain are both moving northeastward (e.g., Rau et al. 2008; Angelier et al. 2009; Hou et al. 2009; Ching et al. 2011). As a result, we must understand the structures of the western Ilan Plain in order to understand the tectonic relationships between the old thrust-and-fold belt and the opening of the Okinawa Trough. Researchers (e.g., Chiang et al. 1979; Shih 2011; 


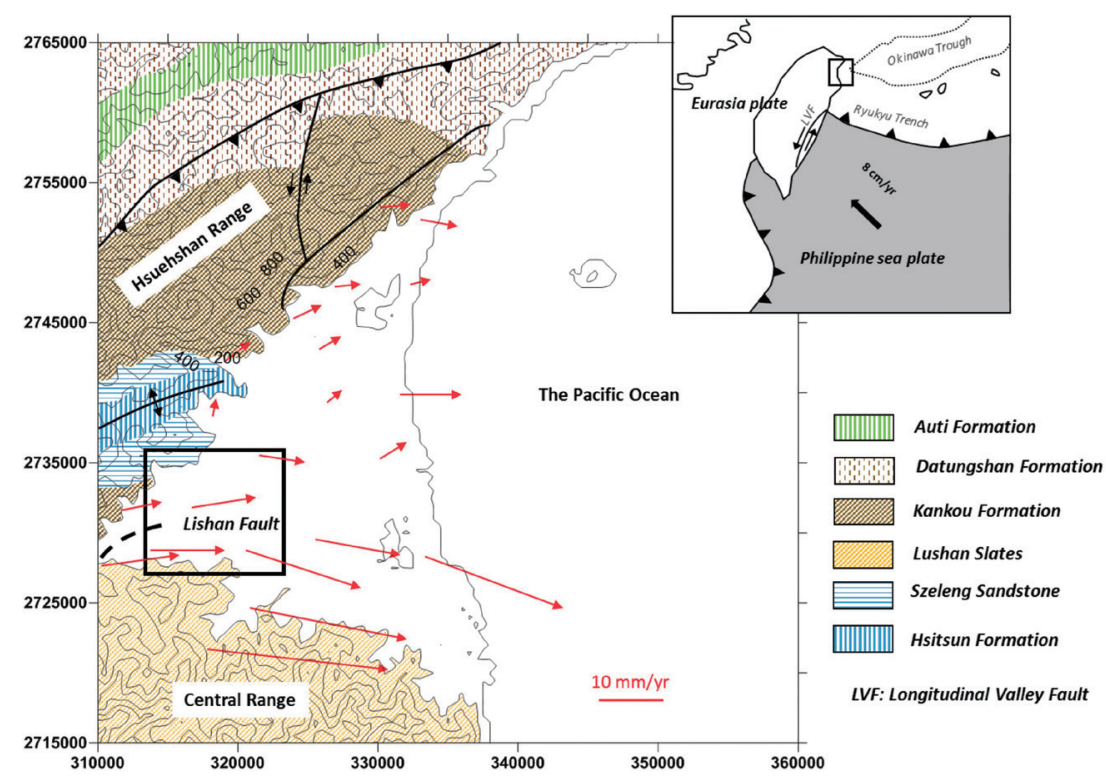

Fig. 1. The geology map of the Ilan Plain in the UTM coordinates. The Lishan Fault separates the geological formations of the Hsuehshan Range from the formations of the Central Range. The black rectangle identifies our research area in the western Ilan Plain. And the red arrows show the horizontal velocity fields of the GPS stations in Ilan relative to the Penghu island by Hou et al. (2009).

Huang 2015; Chung 2016) conducted seismic reflection surveys in the Ilan Plain, yet the thick unconsolidated sediment, the cultural noise, the off-line scattering, and limited shot-gather offset provide limited opportunities to explain the near-vertical structures (Steeples and Miller 1998; Steeples 2005) in this area. For our study, we conducted audio magnetotelluric (AMT) surveys at the western part of the plain, and tried to map the resistivity structures that may be related to the faults in the area. We then used the AMT results to tighten our interpretations of the seismic reflection profiles. Using the re-interpreted structures identified from both the AMT and seismic profiles, we studied the transition zone between the compression and extension structures and their geometric relationships.

\section{STUDY AREA}

The triangular Ilan Plain is bounded by the Hsuehshan Mountain Range in the north, the Central Mountain Range in the south, and the Pacific Ocean in the east. The Lishan fault is located at the western tip of the plain and separates the Hsuehshan Mountain Range from the Central Mountain Range. The Hsuehshan Mountain Range and the Central Mountain Range are composed of pre-collision sediments in the rifting grabens of the Eurasia Continent, and are dominated by the thrust-and-fold structures related to the arccontinent collision (e.g., Brown et al. 2012). Figure 2 shows the geological settings near the research area in the Ilan area. The Central Range is composed mainly of Miocene to Paleogene Lushan slates, while the Hsuehshan Mountain Range consists of meta-sandstones and slates from the Eo- cene to the Miocene. The outcrops in the Hsuehshan Range can be further divided into the Hsitsun slate formation from the Oligocene to the Eocene, the Oligocene Szeleng metasandstone formation, and the Kangkou Argilite formation of the upper Oligocene near our study area. Unconsolidated alluvial deposits from the Lanyang River were laid over the Paleogene rock basement, which exhibits a series of faults (Chiang et al. 1979; Hsu et al. 1996) identified from seismic reflection profiles. In addition, wellbore-drilling data show that, within the last 3000 years, young sediment has deposited itself on the plain at an extremely high deposition rate and has exceeded a 20-m thickness (Chen 2000; CGS 2001). The findings in Chen (2000) also imply that the plain has undergone a rapid subsidence recently. Therefore, it is difficult to observe the fault systems that are related to the opening of the subsiding Ilan Basin under the unconsolidated deposits that range in thickness from $100 \mathrm{~m}$ to over $800 \mathrm{~m}$ on the Ilan Plain.

From their on-land seismic explorations in the Ilan Plain, Chiang et al. (1979) showed that there are mainly EWtrending thrust faults dipping south. However, the recent marine seismic profile off the Ilan Plain shows that a series of EW-trending normal faults dip north in extending directions (Ku et al. 2009). By contrast, recent land seismic reflection surveys suggest that mainly thrust faults exist in the western Ilan Plain, except for the Choushui Fault along the Lanyang River (Shih 2011; Huang 2015; Chung 2016). The resolution and exploration depth are limited owing to both the limited shot-gather offset in the survey design and the out-of-theplane reflections from the off-line geological structures in the land seismic surveys (Steeples 2005). These limitations 
(a)

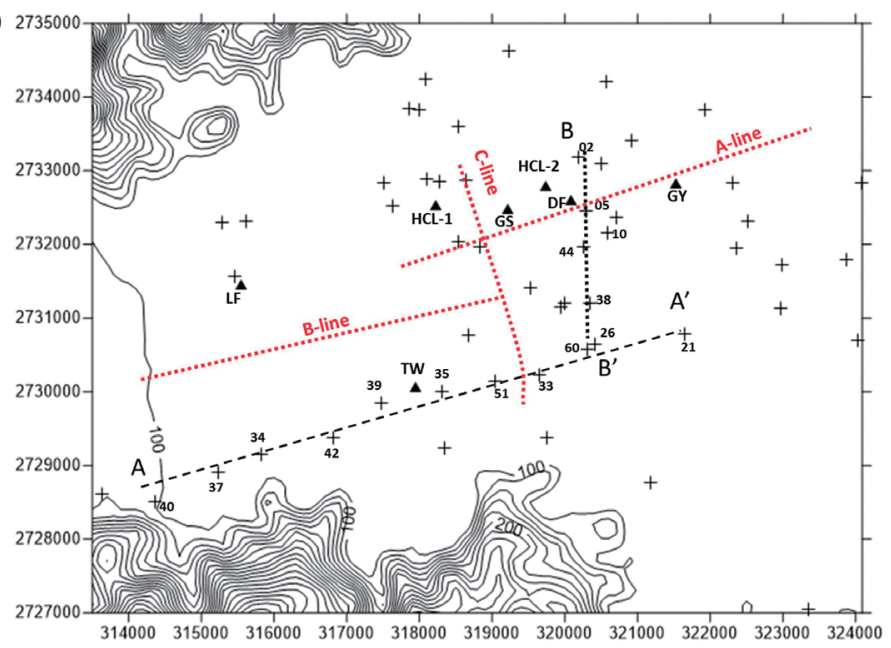

(b)

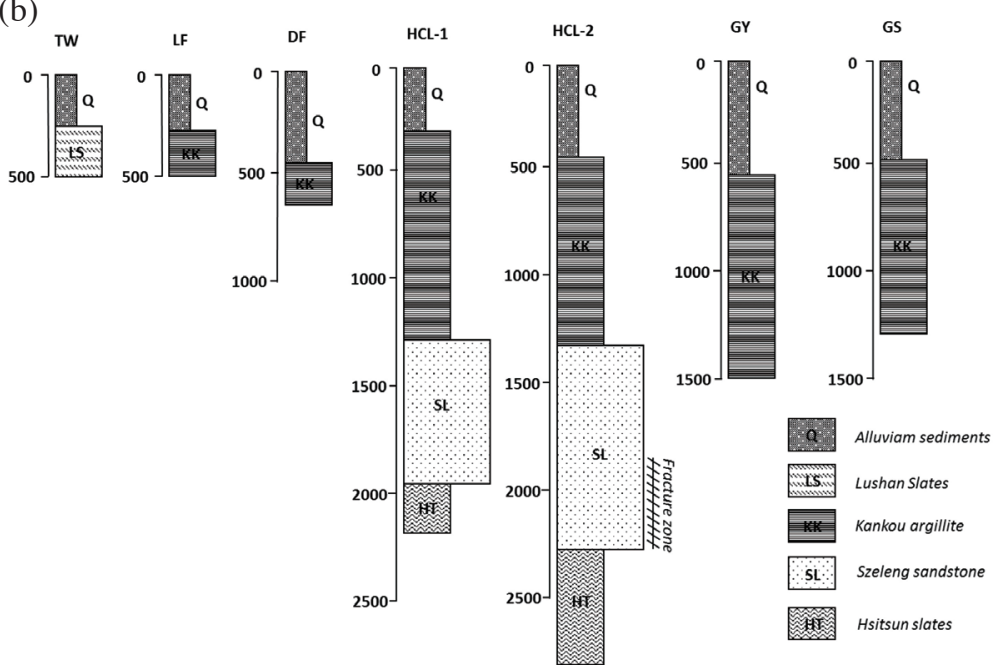

Fig. 2. (a) The locations of our study area's AMT stations and boreholes deeper than $500 \mathrm{~m}$ in the UTM coordinates. The cross symbols are the AMT stations, and the triangles are the sites of boreholes LF, TW, HCL-1, HCL-2, GS, DF, and GY. Dashed lines A-A' and B-B' represents the two AMT profiles for the 1D and 2D inversions. The red dashed A-line, B-line, and C-line indicates the seismic reflection profiles in Huang (2015). (b) The lithology logs of the LF, TW, HCL-1, HCL-2, GS, DF, and GY boreholes.

may yield contradictory explanations of marine seismic and borehole-log phenomena (e.g., Steeples and Miller 1998). Hence, it is necessary to further study the possible geological structures with additional geophysical tools, such as the electromagnetic exploratory tools, to constrain, refine, and strengthen interpretations of seismic phenomena.

\section{SURVEY CONFIGURATIONS AND DATA PROCESSING}

A total of 63 AMT stations were deployed in the western Ilan Plain for imaging the subsurface structures. We recorded the magnetotelluric signals by means of the Phoenix V5-2000 system. First, we divided the collected time-series of the Earth's electrical and magnetic fields into several segments. Using Fourier transformation, we converted the time-series into a power spectrum. With the electric and magnetic spectrums, one can estimate the impedances for different frequency bands. The optimal apparent resistivity and phases were then estimated with statistical robust-fitting of impedances from all segments. Unfortunately, we found that some data from a few sites was unsuitable for further processing because of noisy signals and response impedances. Thus, after reviewing the variation errors of the apparent resistivity and phases, we selected only data from 38 relatively uncontaminated AMT sites (an example as shown in Fig. 3) for the inversion of electrical structures. The likely reasons for the noisy data were electromagnetic noises from human activities such as electric trains and power lines in the nearby populated areas.

To analyze the AMT data, we chose to invert the data of apparent resistivity and phases in the TM mode with both the one-dimensional (1D) and two-dimensional (2D) inversions. We used the 1D inversion code, IPI2WIN (MT) 

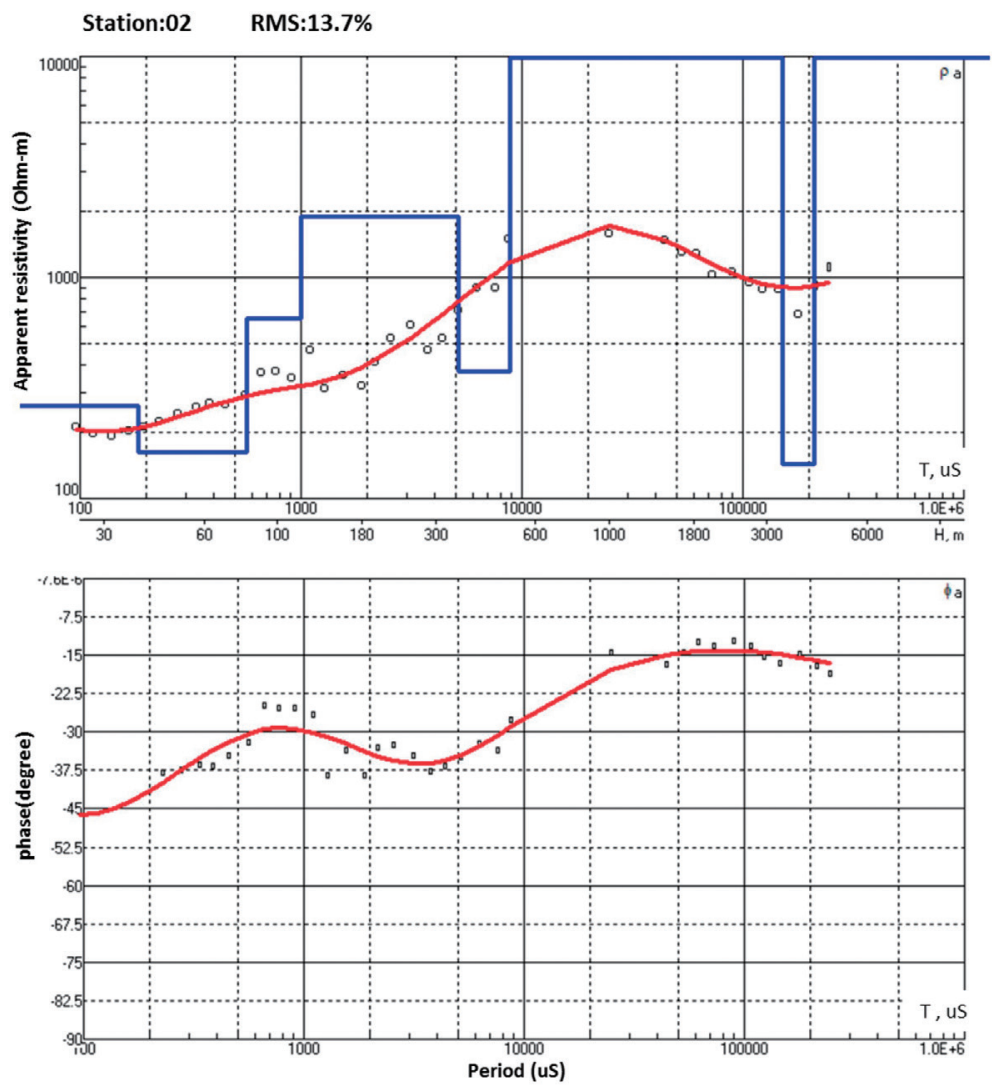

Fig. 3. Upper: the measured apparent resistivities (circles) of different frequencies at the station 02 . The blue line shows the resistivity model after 1D inversion, and the red line is the fitted apparent resistivity curve. Lower: the measured phases (squares) of different frequencies at station 02. The red curve is the fitted phase based on the inverted model.

(Bobachev 2003), for the inversion of magnetotelluric data. Owing to the noisy environment, we selected only those electric-field and magnetic-field data with frequencies from 4 to $10410 \mathrm{~Hz}$ for the inversion. To maintain the consistency of the inversion process, we first inverted the data from a starting station with a uniform resistivity model. Then the inverted results were used as the initial model for inverting the resistivity model of the neighboring station. Finally, we stitched together the inverted results of all stations in order to come up with the "stitched cross-sections" of resistivity. For the 2D inversion, we chose to use an inversion code, OCCAM2DMT V3.0 (Constable et al. 1987; De Groot-Hedlin and Constable 1990), for the inversion of our selected AMT data in the TM mode. The inversion code is an implementation of the general Occam procedure of Constable et al. (1987) and was extended to two dimensions by De Groot-Hedlin and Constable (1990). We carried out the 2D forward calculations by using both code from Wannamaker et al. (1987) and reciprocity to calculate the Jacobian (Pastana de Lugão and Wannamaker 1996). In the area, the unconsolidated sediments can be thicker than $100 \mathrm{~m}$ and are consisted of majorly the gravel and sands. Given a resistivity of around $100-300$ Ohm-m (e.g., Ho et al. 2014) from the surface direct current resistivity measurements, one may expect roughly that the maximum skin depth can be then approach about $2-4 \mathrm{~km}$ if the lowest frequency is $4 \mathrm{~Hz}$ for the AMT surveys.

\section{RESULTS}

\subsection{The Dimensionality Analysis}

Figure 4a shows the rose plots of the impedance, phase tensors, and the tippers produced with the MTpy package (Kirkby et al. 2019) in the study area. The dominated impedance strike is about $175^{\circ}$ and is consistent to the azimuth of the phase tensor. The electric strike estimated from the impedance and phase tensor reveals the possible direction of the shallow geological structures in the N-S direction. On the other hand, the dominant azimuth of the tipper is about $70^{\circ}$, which points to the lower fan and is consistent to the strikes of the normal faults in Ho et al. (2014).

In addition, Fig. $4 \mathrm{~b}$ shows the phase tensor (PT) ellipses (Caldwell et al. 2004), skew angle (Bahr 1987), and the Parkinson-convention induction vectors (IVs) of the MT measurements in the study area produced with the MTpy package (Kirkby et al. 2019). Following the Parkinson convention (Parkinson 1959), the IVs point to the concentration of the electric currents (i.e., the conductive regions) and 


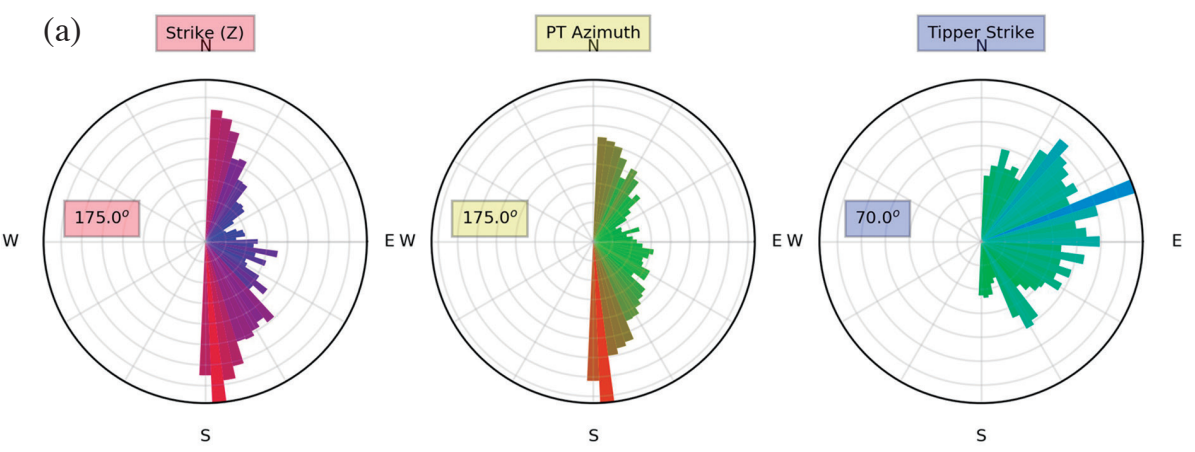

(b)
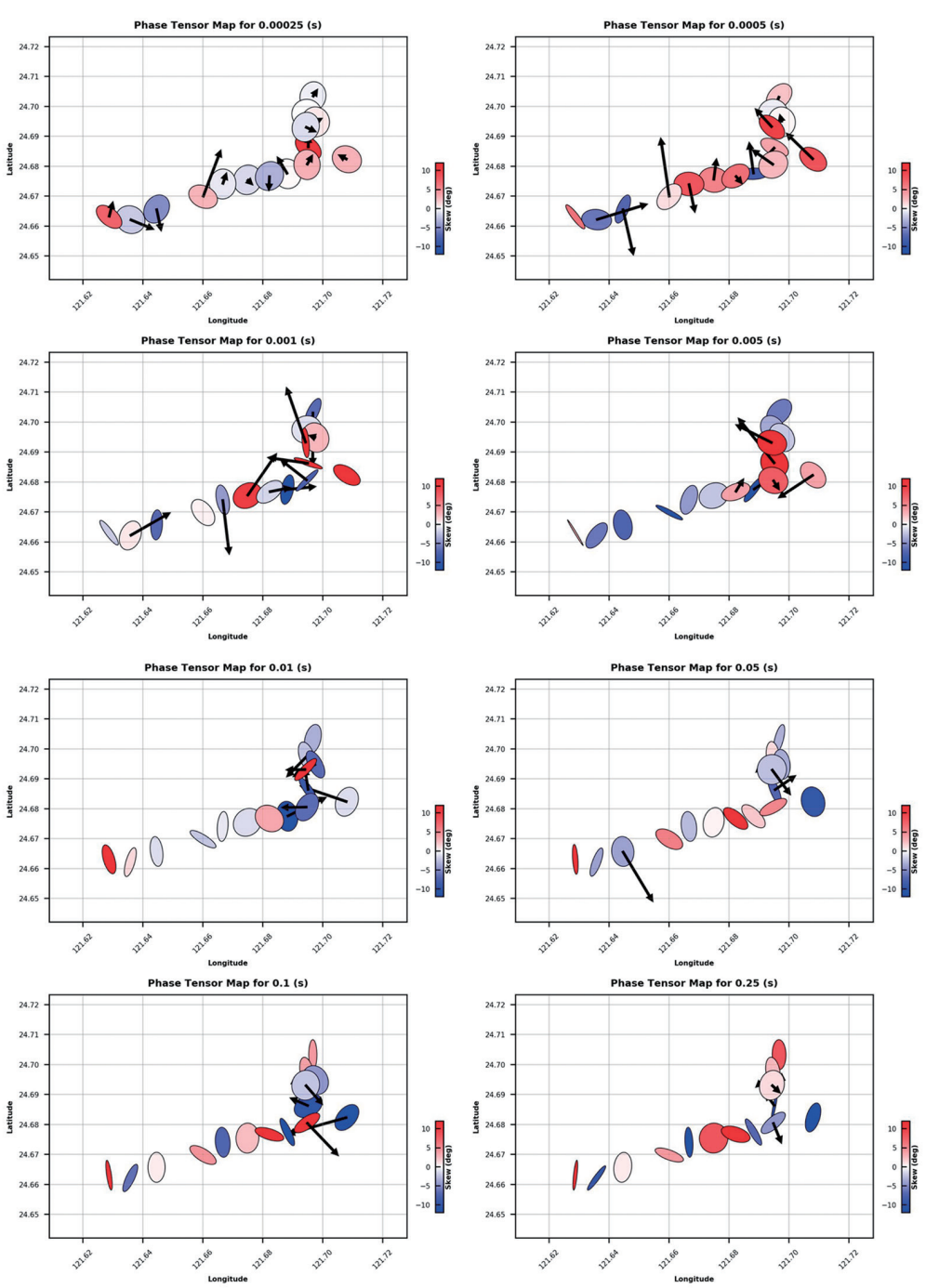

Fig. 4. (a) The rose diagrams of the impedance strikes, the phase-tensor (PT) strikes, and the tipper strikes of the AMT measurements. (b) The phase tensor ellipses and the induction arrows of the AMT measurements at different periods in the study area. Noted that the coordinate system is converted into Latitude/Longitude. 
therefore are used to infer the presence or absence of lateral resistivity variations. In addition, the principle axes of each PT ellipse reflect lateral variations (gradients) in the underlying regional resistivity structures (Caldwell et al. 2004). The skew angle of the PT ellipse indicates the PT's symmetry and can be thought as a measure for 3D effects in the PT responses (Caldwell et al. 2004). In general, the induction arrows perform a random distribution of induction directions in Fig. 4b, which may suggest a relatively complicated geological structure system in the study area. The PT ellipses suggest that the short period measurements exhibit 1D/2D structures, while the period longer than $0.002 \mathrm{~s}$ start to turn into $2 \mathrm{D} / 3 \mathrm{D}$ structures. The findings indicate that a possible interface between the shallow and deep structures, likely the basement of the unconsolidated sediments. The majority of the principle axis of the ellipses are in the N-S direction for the data with period longer than $0.002 \mathrm{~s}$. The fact may imply a possible dominating geological structure system in the rock basement.

The MT data can be separated into two independent modes, TM and TE, corresponding to electric current flow perpendicular and parallel to the strike direction, respectively, in a 2D earth. In previous studies (e.g., Wannamaker et al. 2002; Berdichevsky and Dmitriev 2010), the TM mode can satisfactorily help yield the shallow structures that are perpendicular to the survey lines within $1-2 \mathrm{~km}$ deep. We inverted the data from 46 frequencies between 4 and $10410 \mathrm{~Hz}$ in the transverse mode (TM mode) only in the following studies, since we would like to focus on the shallow structures and the rock basement depths in our 1D and 2D inversion analysis.

\subsection{The 1D AMT Inversions}

After inverting the selected data, we built the stitched E-W resistivity profile, A-A', from a $1 \mathrm{D}$ inversion of the AMT stations (Fig. 5) with the selected stations that line up in the east-west direction. We noticed that the unconsolidated sediments are conductive with a resistivity of less than $1000 \mathrm{Ohm}-\mathrm{m}$ in general, and the sediments are laid above the resistive layer with resistivity higher than $10000 \mathrm{Ohm}$ $\mathrm{m}$ in the image. The 500-m-deep TW borehole is located near the A-A' profile and indicates that the unconsolidated sediments have a thickness of about $245 \mathrm{~m}$ above the slates. Comparing the inverted 1D model with previous studies' records for nearby borehole and seismic survey results (Chen 2014; Huang 2015; Chung 2016), we concluded that the resistive layer is likely the rock basement of the Ilan Basin's sedimentary area. In the A-A' profile, we observed two distinct $1 \mathrm{D}$ resistivity structures between the western and eastern regions at a depth greater than $2000 \mathrm{~m}$. This observation suggests that the western part of the rock basement consists of resistive materials, yet the eastern part of the rock basement is composed of a two-layer resistivity structure with a conductive layer less than $100 \mathrm{Ohm}$-m laid under the resistive rocks at a depth greater than $1500-2000 \mathrm{~m}$. The contact area of the western and eastern parts of the basement is between stations 37 and 34, as indicated by the yellow dashed line in Fig. 5.

Figure 6 shows the stitched resistivity profiles from the 1D inversion results of the north-south B-B' line. In Fig. 6, we can observe the distinctive difference in resistivity between the conductive sediments (with a resistivity less than $1000 \mathrm{Ohm}-\mathrm{m}$ ) and the resistive rock basement (with a resistivity greater than $10000 \mathrm{Ohm}-\mathrm{m}$ ). Both the core records from boreholes HCL-1 and GY agree with the basement depths of the sediments in Fig. 6. In addition, we observed two different basement-resistivity structures between the northern and southern part of the profile, as previously shown in the A-A' profile. The northern part of the rock basement consists of resistive materials within a depth of $3000 \mathrm{~m}$. By contrast, the southern part of the rock basement comprises two resistivity layers, which include a resistive rock layer and, underneath it, a conductive rock layer. The contact area of the two parts of the rock basement is between stations 5 and 10 . The borehole log records show that the rock basement consists of the Kangkou, Szeleng, and Shitsun formations of the Hsuehshan group in HCL-1, yet the basement is likely the Lushan slates in the borehole TW. As a result, the contacts between the two different resistivity structures found in the A-A' and B-B' profiles from the 1D inversion results suggest that tectonic contact exists between the rocks of the Hsuehshan Group and the Lushan Slates. Unfortunately, there are few boreholes deeper than $2000 \mathrm{~m}$ to verify the findings from our AMT results. Further drilling investigations deeper than $2000 \mathrm{~m}$ are needed in the contact area to verify the findings regarding the discontinuity of the resistivity basement structures.

\subsection{The 2D AMT Inversions}

With 38 AMT stations, we selected data from only 18 stations, which lined up on two perpendicular lines, A-A' and B-B', as shown in the $1 \mathrm{D}$ stitched profiles for the $2 \mathrm{D}$ inversions. Figure 7 presents the inverted resistivity profiles from the $2 \mathrm{D}$ inversion of the east-west profile, A-A'. It is difficult to find the sharp boundary between the unconsolidated sediments and the resistive rock basement in the profile, since the inversion scheme involves the smoothing algorithm. We show only the $2 \mathrm{D}$ profile within a depth of $2000 \mathrm{~m}$ because the rock basement comprises mainly resistive rocks and because conductive structures such as faults are easier to highlight through 2D inversion. In the inverted image in Fig. 7, we observed some distinctive high-angle conductive structures that cut through the resistive basement rocks within a depth of $2000 \mathrm{~m}$. The structures include those indicated by the red dotted lines (a, b, c, and d) in Fig. 5, and they may represent the faults in the area because the rock 


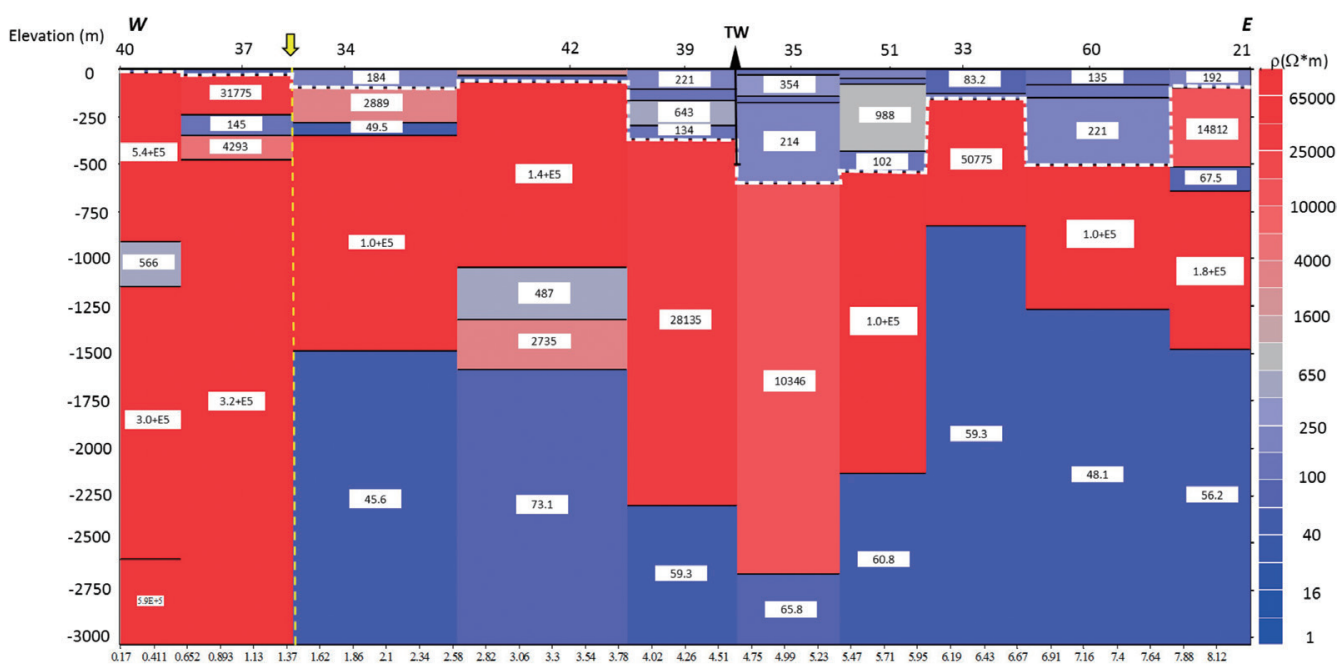

Fig. 5. The stitched resistivity profiles from the $1 \mathrm{D}$ inversion of the A-A' line. The white dotted line shows the possible basement of quaternary sediments. We observed two different resistivity structures under the basement between the western and eastern parts of the profile. The contact of the two regions (the yellow dashed line) is located between stations 37 and 34 .

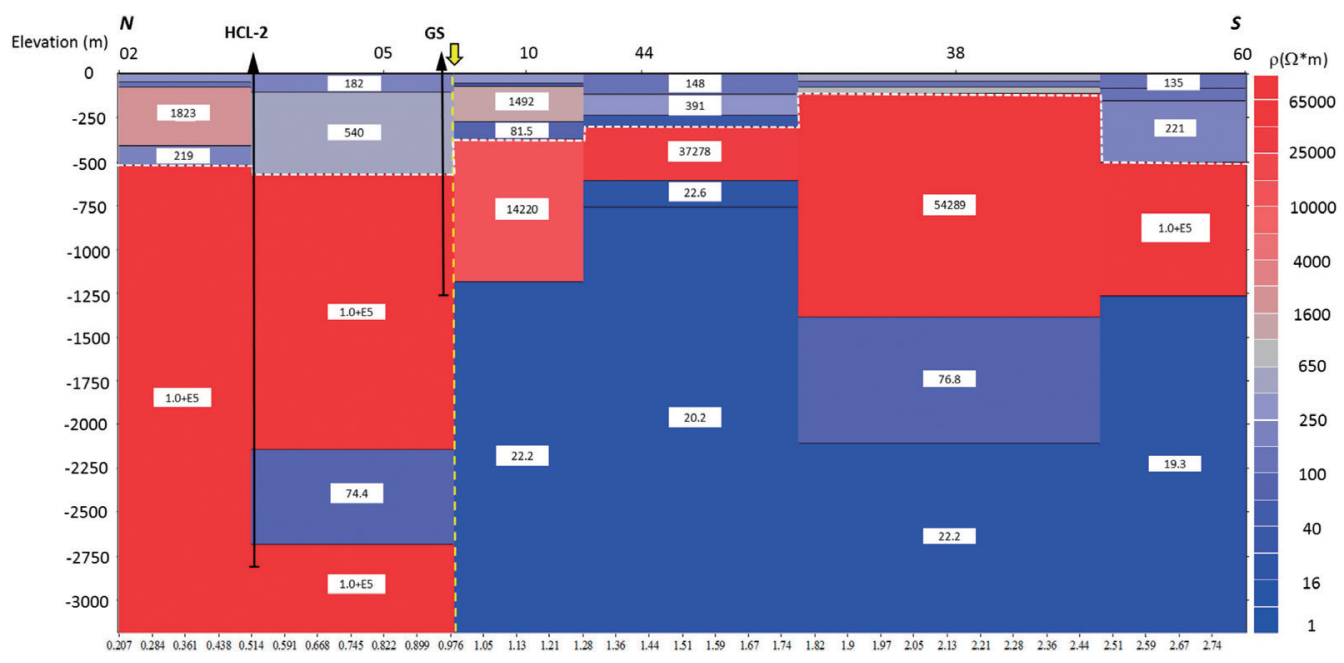

Fig. 6. The stitched resistivity profiles from the 1D inversion of the B-B'. The white dotted line shows the possible basement of quaternary sediments. Again, we observed two different resistivity structures under the basement between the northern and southern parts of the profile. The contact of the two regions is located between stations 5 and 10 .

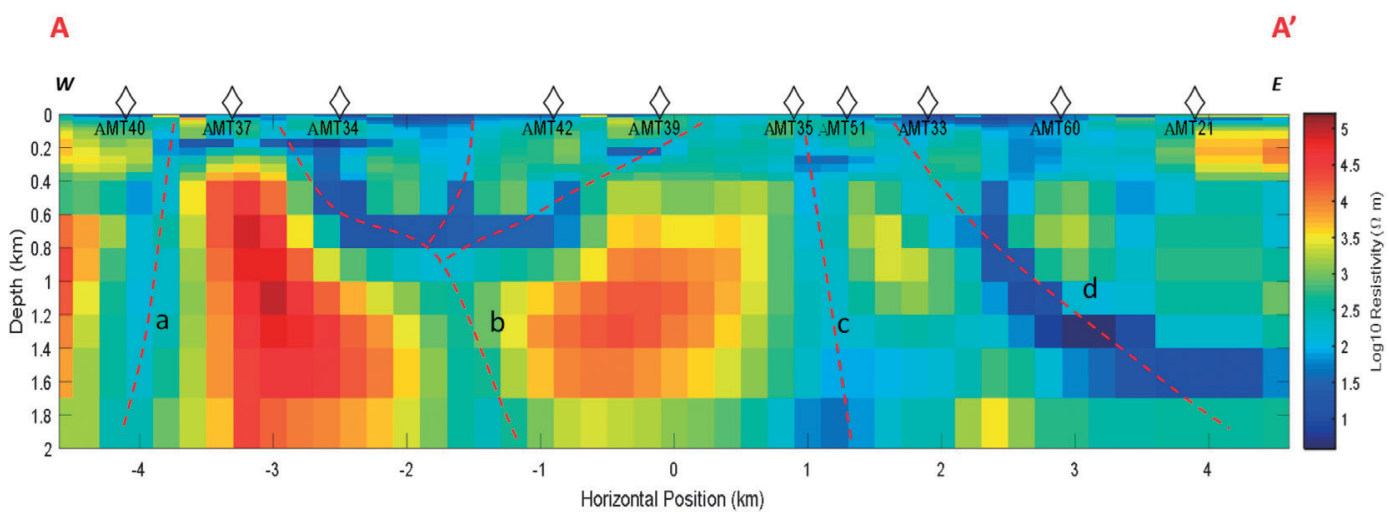

Fig. 7. The inverted resistivity profiles from the $2 \mathrm{D}$ inversion of the A-A'. The red dotted lines show the possible fault structures a, b, c, and d. These structures exhibit relatively low resistivity and high tilting angles. 
basement consists mostly of relatively resistive rocks within a depth of $2000 \mathrm{~m}$. When we compare the $2 \mathrm{D}$ model with the results from previous studies' 1D inversions and seismic surveys (Huang 2015; Chung 2016), we can see that Fig. 7's conductive structure $b$, which is located between stations 37 and 39, seems to have developed several fault branches near the surface. The entire flower structure of structure $b$ has a surface width of about $2.5 \mathrm{~km}$, and these surface fault branches merge together and dip toward the east at a depth greater than $1 \mathrm{~km}$. The conductive structure $\mathrm{b}$ dips to the east at an angle of about $75^{\circ}$ at a depth greater than $1 \mathrm{~km}$, and its location is likely associated with the boundary contact between the Hsuehshan Group and the Lushan Slates as indicated in the 1D inversion. By contrast, the conductive structure a dips toward the west. As for structure c, it is located between AMT stations 35 and 51, and dips toward the east at a high angle. Conductive structure $\mathrm{d}$ dips toward the east at an angle lower than that of structures $b$ and c.

Figure 8 illustrates the inverted resistivity profiles from the $2 \mathrm{D}$ inversion of $\mathrm{B}-\mathrm{B}$ '. We observed that the fracture zones registered from the projected boreholes HCL1 and GY are consistent with conductive structure $\mathrm{f}$ in Fig. 8. After comparing the inverted B-B' profile with the borehole records, we concluded that conductive structures e and $f$ are associated with the fault fracture zones. Conductive structure e between AMT stations 01 and 02 dips toward the north. By contrast, structure f not only dips toward the north at an angle of about $70^{\circ}$ and at a depth greater than $0.8 \mathrm{~km}$, but also splits into two fault ruptures at a depth less than $0.8 \mathrm{~km}$. The two shallow branches of conductive structure $f$ are likely the flower structures of the faulting structure, and the entire flower structures of $f$ have a surface width of about $1 \mathrm{~km}$ in B-B'. Moreover, the location of $\mathrm{f}$ is associated with the likely boundary between the Hsuehshan Group and the Lushan Slates as indicated in the 1D inversion. In the discussion that follows, we compare the AMT results with survey data about nearby seismic activity in order to explore two critical topics: first, the fault characteristics and their possible orientations; and second, the likely paleo-thrust boundary between the Lushan Slates and the Hsuehshan Groups.

\section{DISCUSSION}

Because the 1D inversion results reveal a distinctive boundary between the rock basement and the unconsolidated sediments, we can make an interpolated map of the basement depths by using all the AMT stations (cross dots) across the study area, as shown in Fig. 9, with the Kriging method. We verified the estimated depths of the unconsolidated sediments' basement by using core records from six boreholes: HCL-1, HCL-2, DF, GY, LF, and TW, all of which are deeper than $500 \mathrm{~m}$ (Wang et al. 2017a). The locations and geology columns of the boreholes can be found in Fig. 2 .
Table 1 shows the results from our comparison between the borehole records' estimated basin depths and the AMT estimated results. By subtracting the true depths from the estimated depths of the rock basement, we concluded that the average error of the depth estimation is about $42 \mathrm{~m}$, and the root-mean-square of errors is about $105 \mathrm{~m}$. The three boreholes LF, TW, and GY are located in areas that have not only relatively few AMT stations but also relatively high errors of estimation. Of the three boreholes, the GY borehole has the highest error of estimation, which comes in at about $240 \mathrm{~m}$. The high estimation error is reasonable in our view because the GY borehole is the one that is located far from any available AMT stations and should have high interpolation uncertainties. If borehole GY is excluded from the data, the root-mean-square of errors decreases to about $58 \mathrm{~m}$.

Previous research (Huang 2015; Chung 2016; Shih 2011) involved seismic surveys with the $40-\mathrm{Hz}$ geophones and a Vibroseis source with a sweep frequency between 10 and $300 \mathrm{~Hz}$. The seismic profiles, however, are saturated with scattering and multiples for regions deeper than $1200 \mathrm{~m}$. We selected the two profiles near the A-A' and B-B' AMT profiles and projected the AMT images onto the seismic profile in the Figs. 10 and 11, respectively. The AMT images provide additional information about the highangle faults and fractures. This information helps constrain our interpretations of the seismic profiles, since the onshore seismic surveys usually have insufficient offsets for illuminating the high-angle structures. In the overlapped A-A' profile (Fig. 10a), we found that the seismic horizons were truncated and displaced at the locations where the AMT image shows resistivity less than $500 \mathrm{Ohm}-\mathrm{m}$. We matched the seismic horizons with the AMT estimated basement depths, and we depicted the bottom of the unconsolidated sediments as Fig. 10a's white line. From the displacement of the contact between the sediments and the rock basement, we found that most of the faults were high-angle normal faults or oblique-slip faults with a displacement ranging from a few to tens of meters, as shown in Fig. 10b. Moreover, we identified the discordance between the rocks with tight-to-closed folding structures in the western part of the profile and the rock formation with open folds in the eastern part of the A-A' profile (Fig. 8b). From the borehole data, we concluded that the two formations were perhaps, respectively, the rock formations in the Hsuehshan Group and the Lushan Slates. The discordant contact that gently dips to the east may be the paleo-thrust fault that thrusts the Miocene Lushan slates onto the younger rocks of the Hsuehshan group.

The overlapped B-B' profile shows the offsets of the reflections at the locations that have resistivity less than 500 Ohm-m in the AMT image (Fig. 11a). By comparing the seismic reflections and the MT estimated basement depths with one another, we identified the contacts between the sediments and the rock basement (see Fig. 11). Figure 11b 


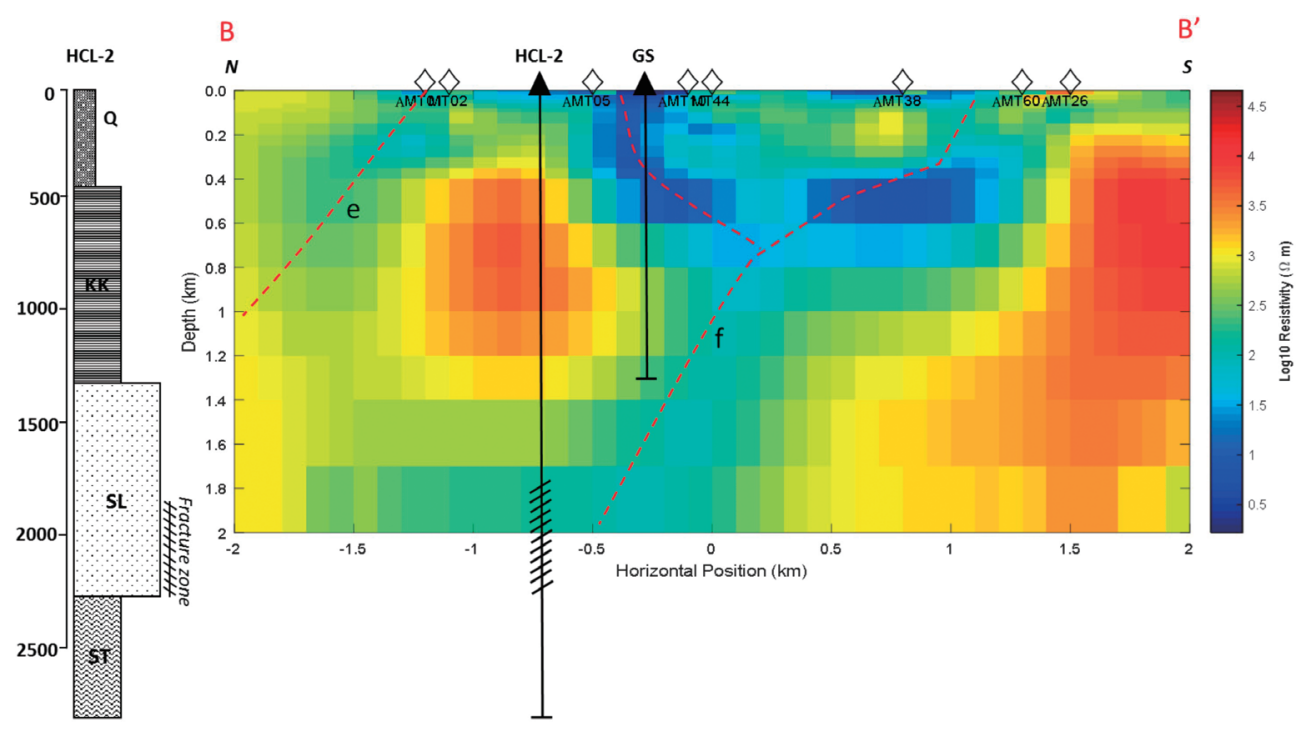

Fig. 8. Inverted resistivity profiles from the $2 \mathrm{D}$ inversion of the B-B'. The red dotted line shows the possible fault structures e and f. Nearby boreholes HCL-1 and GY are projected on the B-B' profile. The slash areas show the registered fractured zone in boreholes HCL-1 from the drilling logs. The geological column from Borehole HCL-1 is shown at the right side of the profile. Q denotes the unconsolidated sediments; KK, the Kangkou Argillite; SL, the Szeleng formation; and LS, the Lushan slates.

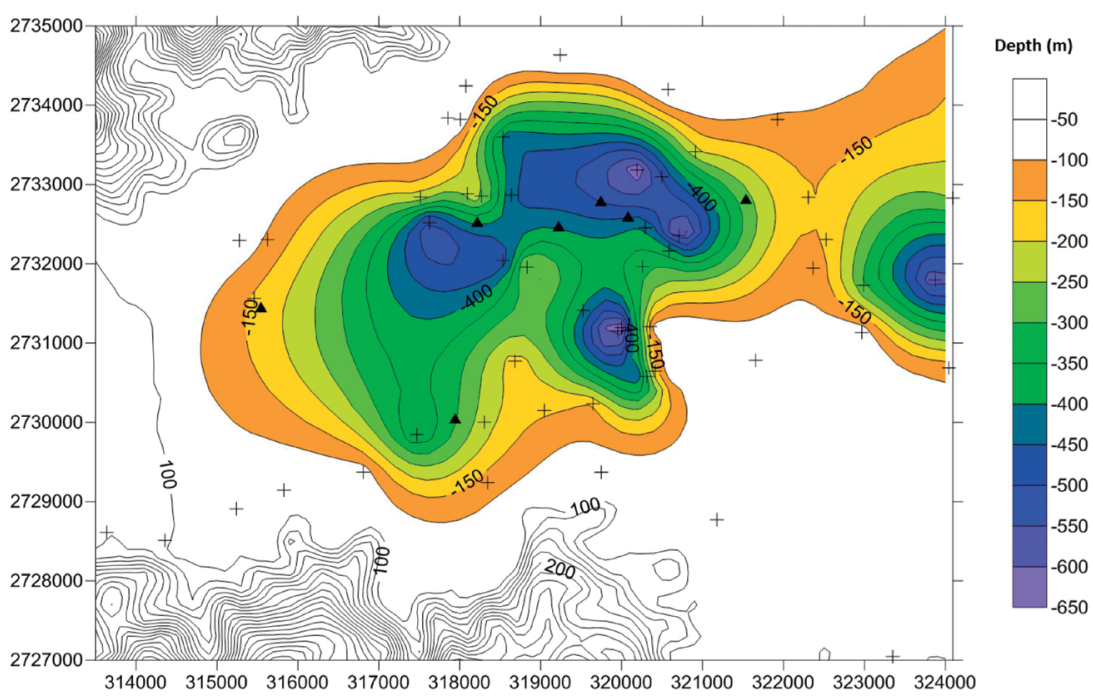

Fig. 9. The interpolated basement topography maps using all the AMT stations (cross symbols) across the study area. The triangles represent the locations of the wells in the area.

Table 1. Comparing the seven wells with one another in terms of (1) well depth, (2) basement depth, and (3) estimated basement depth.

\begin{tabular}{c|ccc}
\hline Well & Well depth $(\mathbf{m})$ & Basement depth $(\mathbf{m})$ & Estimated basement depth $(\mathbf{m})$ \\
\hline HCL-1 & 1400 & 395 & 396 \\
HCL-2 & 2800 & 470 & 488 \\
DF & 602 & 469 & 459 \\
GS & 1300 & 480 & 412 \\
TW & 500 & 245 & 335 \\
LF & 502 & 260 & 176 \\
GY & 1500 & 520 & 281 \\
\hline
\end{tabular}



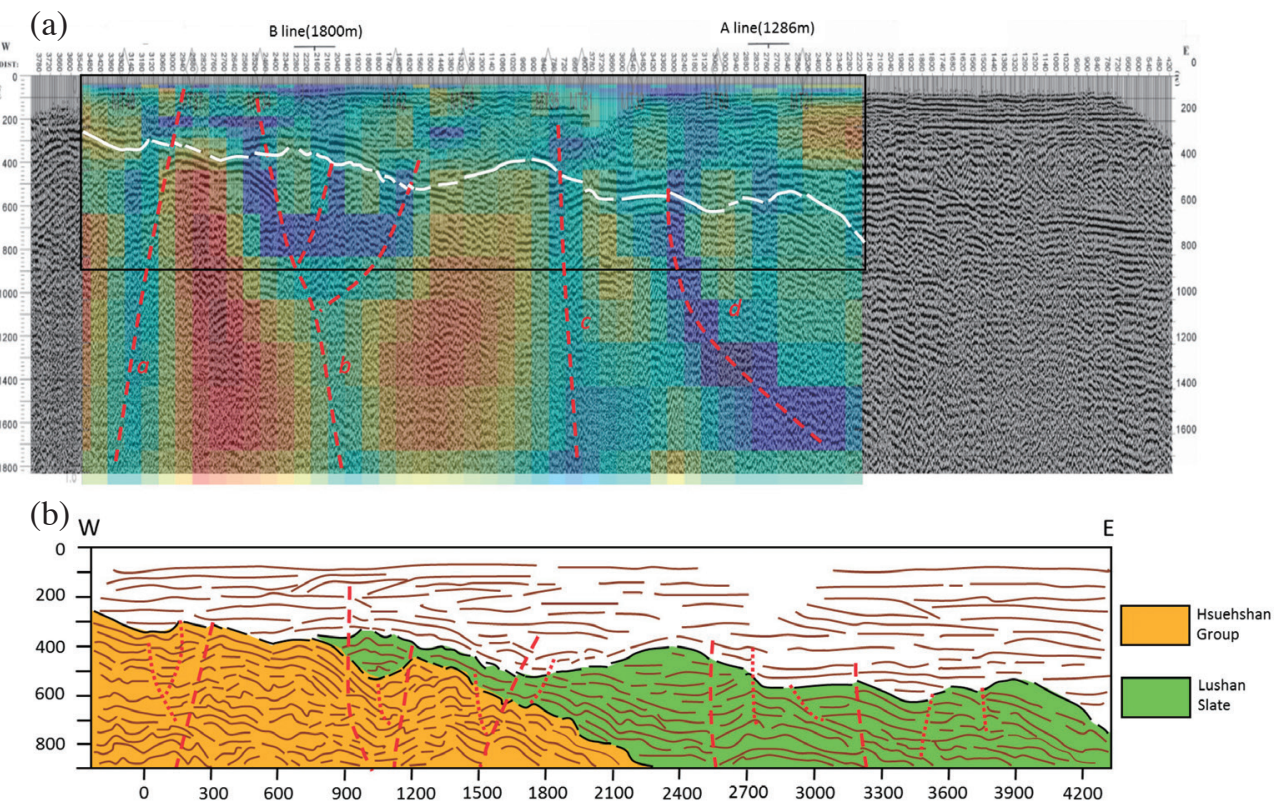

Fig. 10. (a) Structures identified from the AMT inverted 2D image of the A-A' overlapped onto the seismic profile edited from Huang (2015) and Chung (2016), with the survey line being close to the MT survey line. The white broken line shows the basement of the unconsolidated sediments. Conductive structures a, b, c, and d are likely the high-angle strike-slip faults from the offset of the seismic reflection profile. (b) The interpretation of the seismic profile in the black region in (a). Red dashed lines show the major structures correlated to the MT conductive regions, and the red dotted lines show minor structures identified from the seismic profile.
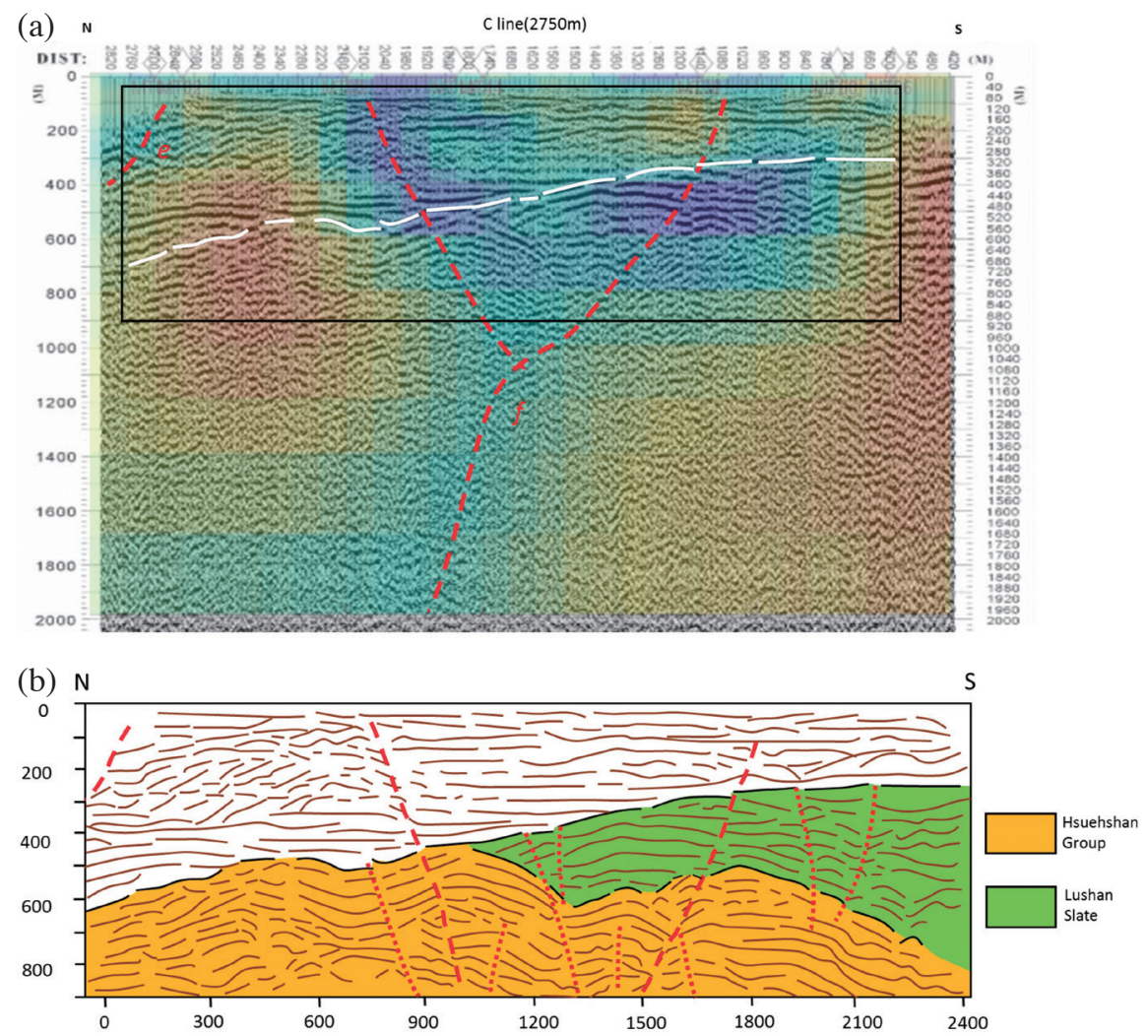

Fig. 11. (a) Structures identified from the MT inverted 2D image of the B-B' overlapped onto the seismic profile edited from Huang (2015) and Chung (2016), with the survey line being close to the MT survey line. The white broken line shows the basement of the unconsolidated sediments. Conductive structures e and $\mathrm{f}$ are likely high-angle normal faults from the seismic interpretations. (b) The interpretation of the seismic profile in the black region in (a). Red dashed lines show the major structures correlated to the MT conductive regions, and red dotted lines show minor structures identified from the seismic profile. 
shows our interpretation of the seismic reflection profile from ground surface to a depth of about $0.9 \mathrm{~km}$. From the offsets of the reflections, we found that most of the faults are high-angle normal faults in the B-B' profile. We also observed that these fault systems dip toward the north in the southern part of the B-B' profile, and dip toward the south in the northern part of the profile. These normal faults have an offset that range, in length, from a few meters to ten meters. The reflection structures in B-B' profile was similar to the A-A' profile, insofar as we observed discordance between the Hsuehshan Group and the Lushan slates. The contact between the two rock groups dips toward the south at an angle of about $35^{\circ}$ in the B-B' profile. The low-angle contact is probably the ancient thrust fault between the Hsuehshan Group rocks and the Lushan slates.

From the dimensional analysis of the AMT measurements, we discovered that the geological structures in the $\mathrm{N}-\mathrm{S}$ direction may be the dominant ones in the study area. We also observed the N-S trending strike-slip or oblique-slip faults from the integrated analysis using both the AMT images and the seismic reflection profiles. Figure 12 illustrates our explanations of the geological structures in the western Ilan Plain under the unconsolidated sediments integrated from the seismic exploration and AMT results. The black dashed line indicates the contact between the Hsuehshan Group and the Lushan slates. This contact may represent a paleo-thrust fault that thrust the Lushan slates onto the Hsuehshan Group before the development of the rifting normal fault system. In addition, after comparing the conductive structures with the seismic profiles, we concluded that the conductive structures can be related to the faults with obvious offsets of reflection surfaces in the seismic profiles. The red dotted lines in Fig. 12 represent the possible locations of the normal and strike-slip faults, as identified from the AMT and seismic reflection results. Several E-W trending normal faults such as the Niudou, Choushi, and the Zailian faults were identified from the outcrops or the geophysical investigations near our study area in previous studies (Lai et al. 2009; Ho et al. 2014; Wang et al. 2017a, b). The Niudou, Choushui, and Zailian faults in Fig. 12 can be correlated to the conductive structures $\mathrm{f}$, e, and c shown in Figs. 7 and 8. The fault planes of the Zailian and the Niudou normal faults dip to north, and the Choushui fault dips south. The normal faults, including the Zailian, Choushui, and Niudou faults, form the graben of rock basement laid under the thick unconsolidated fluvial sediments. In addition, the strike-slip faults oriented in the north-south direction appear to be younger than the normal faults, since the former faults seem to have truncated the normal faults and dislocated the graben (see Fig. 12). Among the strike-slip faults, the Juntao fault seems to be an important boundary that divides the normal fault system into the northeast-oriented one in the western part of the study area and the southeast-oriented system in the eastern study area. The Juntao fault and the two strike-slip faults, a and b in Fig. 12, are left-lateral faults. By contrast, faults $d$ and $g$ in the eastern study area are right-lateral faults. Therefore, the results of our study suggest that the Juntao fault should represent an important boundary for tectonic

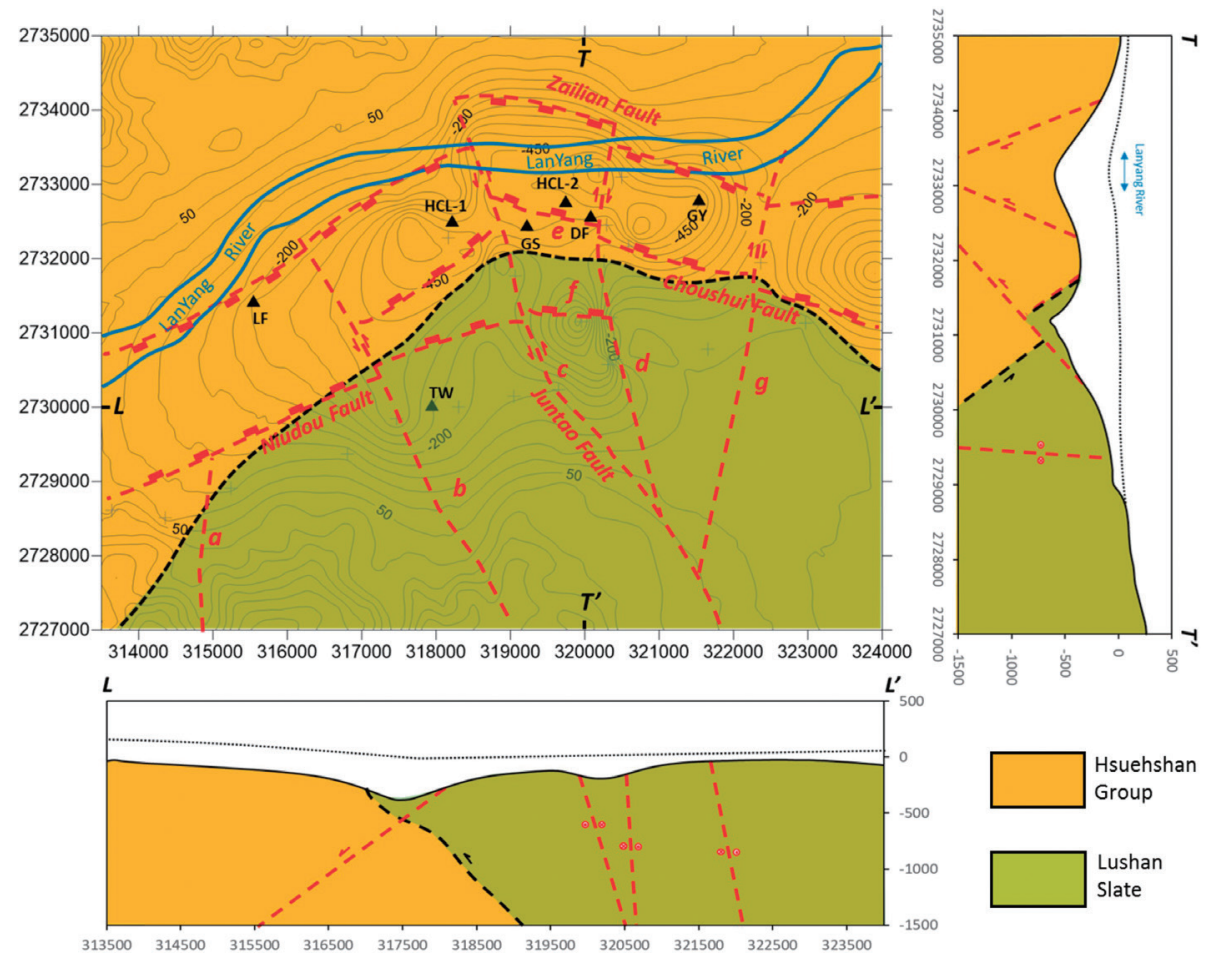

Fig. 12. Preliminary explanation - based on the seismic and AMT-survey results - for the geological structures in the eastern Ilan Plain. 
stress orientations in the western tip of the Ilan Plain. The offset movements of these young strike-slip faults accommodates the rotation of the rock-basement blocks, and agree with the observations from the horizontal velocity fields of the GPS stations in Ilan relative to the Penghu island by Hou et al. (2009).

Huang et al. (2012) proposed that the southward opening of the Okinawa Trough pushes the westernmost Ryukyu arc southward, and the northern part of the Central Range moves with the arc to southeastward. The driving of the opening mechanism is bending the northern Central range and creates the Ilan Plain. The strike-slip faults associated with the bending blocks in the northern Central range is the results of the opening Okinawa Trough. On the other hand, Angelier et al. (2009) suggested that the Ilan plain were affected by not only the Okinawa extension, but also the extrusion of the Taiwan orogenic belt. The former causes the normal faulting system in roughly the E-W direction, and the later induced a lot of $\mathrm{N}-\mathrm{S}$ trending strike-slip faults in the region. In this study, we discovered that the EW-trending graben and the associated normal fault systems are offset by the NS-trending strike-slip faults in the western part of the Ilan plain. The findings may suggest that the influence of the strike-slip faulting related has reset the stress state of the normal faulting system in the western tip and southern part of the Ilan plain, although active normal faults is still observed in the eastern Ilan plain and the offshore. And the onset of the N-S trending strike-slip faults to the E-W trending normal fault system also explains the facts that there is no distinct normal fault scarps in the southern Ilan plain as pointed out by Angelier et al. (2009).

\section{CONCLUSIONS}

In this study, we used the audio-magnetotelluric (AMT) method to depict the fault systems that are under thick fluvial sediments in the western Ilan Plain, which is thought to be influenced by the extension of the rifting Okinawa Trough. We offer preliminary explanations for the geological structures in the western Ilan Plain. We delineate the boundary between the Hsuehshan Group and the Lushan slates-a boundary that may represent an old fault contact that came into existence before the development of the rifting normal fault system. From the inverted 1D and 2D AMT results, as well as the seismic reflection results, we depict normal fault systems, including primarily the Zailian, Choushui and $\mathrm{Ni}-$ udou faults, which are oriented in an east-west direction, and the strike-slip faults, which are oriented in a mostly northsouth direction. We also argue that the strike-slip faults appear to be younger than the normal faults, since the former faults truncated the normal faults and resulted in the dislocation of the graben. Among the strike-slip faults, the Juntao fault seems to be an important boundary that separates the normal fault system into two minor systems that have dif- ferent orientations. Moreover, the strike-slip faults seem to be left-lateral faults to the west of the Juntao fault, but likely show right-lateral features to the right of the Juntao fault. The findings from the seismic reflection and magnetotelluric results suggest that the Juntao strike-slip fault should represent an important boundary for tectonic stress orientations in the western tip of the Ilan Plain.

In addition, Angelier et al. (2009) proposed that the active Ilan plain were affected by two tectonic regimes, including the Okinawa extension, which results in the E-W trending structural system, and the extrusion of the Taiwan orogenic belt, which causes the N-S trending strike-slip fault system. In the study we discovered that the young strike-slip faults truncate the normal fault systems in the southern Ilan plain. And the findings from our AMT measurements and reinterpreted seismic profiles may provide evidences that the extrusion regime may have gradually taken over the regional stress state and reset the regional stress-strain conditions that was one dominated by the Okinawa extension.

Acknowledgements The study is founded by the Ministry of Science and Technology (MOST) of Taiwan under the project No. 104-2116-M-008-017- and 103-2116-M-008-025-

\section{REFERENCES}

Angelier, J., T.-Y. Chang, J.-C. Hu, C.-P. Chang, L. Siame, J.-C. Lee, B. Deffontaines, H.-T. Chu, and C.-Y. Lu, 2009: Does extrusion occur at both tips of the Taiwan collision belt? Insights from active deformation studies in the Ilan Plain and Pingtung Plain regions. Tectonophysics, 466, 356-376, doi: 10.1016/j.tecto.2007.11.015. [Link]

Bahr, K., 1987: Interpretation of the magnetotelluric impedance tensor: Regional induction and local telluric distortion. J. Geophys., 62, 119-127.

Berdichevsky, M. N. and V. I. Dmitriev, 2010: Models and Methods of Magnetotellurics, Springer Science \& Business Media, 564 pp.

Bobachev, A., 2003: Resistivity sounding interpretation IPI2WIN version 3.0.1, Moscow State University, Moscow.

Brown, D., J. Alvarez-Marron, M. Schimmel, Y.-M. Wu, and G. Camanni, 2012: The structure and kinematics of the central Taiwan mountain belt derived from geological and seismicity data. Tectonics, 31, TC5013, doi: 10.1029/2012tc003156. [Link]

Caldwell, T. G., H. M. Bibby, and C. Brown, 2004: The magnetotelluric phase tensor. Geophys. J. Int., 158, 457-469, doi: 10.1111/j.1365-246x.2004.02281.x. [Link]

CGS, 2001: Groundwater monitoring network in Taiwan: The hydro-geology survey in the Chianan Plain and Lanyang Plain, Central Geological Survey. 
Chen, K.-Y., 2014: A Study on Structural Development from Orogenic Belt to Extensional Backarc Setting in Northern Taiwan and its Offshore Area. Ph.D. Thesis, National Central University, Taiwan, 199 pp.

Chen, W. S., 2000: The study of sediments, depositional environments and stratigraphic correlations in the Lanyang Plain. Report of Groundwater Monitoring Network in Taiwan Plan, Central Geological Survey Press, Taipei, 48 pp.

Chiang, S. C., J. J. Lin, C. R. Y. Chang, and T. M. Wu, 1979: A preliminary study of the Chingshui geothermal area, Ilan, Taiwan. Proceeding of the Fifth Geothermal Reservoir Engineering Workshop, Stanford University, Stanford, California, USA, 249-254.

Ching, K.-E., R.-J. Rau, K. M. Johnson, J.-C. Lee, and J.-C. Hu, 2011: Present-day kinematics of active mountain building in Taiwan from GPS observations during 1995-2005. J. Geophys. Res., 116, doi: 10.1029/2010jb008058. [Link]

Chung, C.-T., 2016: Exploration of the geothermal structures in Sansing, Ilan. Master Thesis, National Central University, Taiwan, 128 pp.

Constable, S. C., R. L. Parker, and C. G. Constable, 1987: Occam's inversion: A practical algorithm for generating smooth models from electromagnetic sounding data. Geophysics, 52, 289-300, doi: 10.1190/1.1442303. [Link]

De Groot-Hedlin, C. D. and S. C. Constable, 1990: Occam's inversion to generate smooth, two-dimensional models from magnetotelluric data. Geophysics, 55, 16131624, doi: 10.1190/1.1442813. [Link]

Ho, C. S., 1986: A synthesis of the geologic evolution of Taiwan. Tectonophysics, 125, 1-16, doi: 10.1016/00401951(86)90004-1. [Link]

Ho, G.-R., P.-Y. Chang, W. Lo, C.-M. Liu, and S.-R. Song, 2014: New evidence of regional geological structures inferred from reprocessing and resistivity data interpretation in the Chingshui-Sanshing-Hanchi area of southwestern Ilan County, NE Taiwan. Terr. Atmos. Ocean. Sci., 25, 491-504, doi: 10.3319/ TAO.2014.01.24.01(TT). [Link]

Hou, C.-S., J.-C. Hu, K.-E. Ching, Y.-G. Chen, C.-L. Chen, L.-W. Cheng, C.-L. Tang, S.-H. Huang, and C.-H. Lo, 2009: The crustal deformation of the Ilan Plain acted as a westernmost extension of the Okinawa Trough. Tectonophysics, 466, 344-355, doi: 10.1016/j.tecto.2007.11.022. [Link]

Hsu, S.-K., J.-C. Sibuet, and C.-T. Shyu, 1996: High-resolution detection of geologic boundaries from potentialfield anomalies: An enhanced analytic signal technique. Geophysics, 61, 373-386, doi: 10.1190/1.1443966. [Link]

Huang, C.-C., 2015: Investigating underground structures of geothermal well sites by seismic reflection in the
Ilan Plain, Taiwan. Master Thesis, National Central University, Taiwan, 89 pp.

Huang, H.-H., J. B. H. Shyu, Y.-M. Wu, C.-H. Chang, and Y.-G. Chen, 2012: Seismotectonics of northeastern Taiwan: Kinematics of the transition from waning collision to subduction and postcollisional extension. J. Geophys. Res., 117, doi: 10.1029/2011jb008852. [Link]

Kirkby, A. L., F. Zhang, J. Peacock, R. Hassan, and J. Duan, 2019: The MTPy software package for magnetotelluric data analysis and visualisation. Journal of Open Source Software, 4, doi: 10.21105/joss.01358. [Link]

Ku, C.-Y., S.-K. Hsu, J.-C. Sibuet, and C.-H. Tsai, 2009: The Neo-tectonic structure of the southwestern tip of the Okinawa Trough. Terr. Atmos. Ocean.Sci., 20, 749759, doi: 10.3319/TAO.2008.09.01.01(OC). [Link]

Lai, K.-Y., Y.-G. Chen, Y.-M. Wu, J.-P. Avouac, Y.-T. Kuo, Y. Wang, C.-H. Chang, and K.-C. Lin, 2009: The 2005 Ilan earthquake doublet and seismic crisis in northeastern Taiwan: Evidence for dyke intrusion associated with on-land propagation of the Okinawa Trough. Geophys. J. Int., 179, 678-686, doi: 10.1111/j.1365246x.2009.04307.x. [Link]

Parkinson, W. D., 1959: Directions of Rapid Geomagnetic Fluctuations. Geophys. J. Int., 2, 1-14, doi: 10.1111/j.1365-246X.1959.tb05776.x. [Link]

Pastana de Lugão, P. and P. E. Wannamaker, 1996: Calculating the two-dimensional magnetotelluric Jacobian in finite elements using reciprocity. Geophys. J. Int., 127, 806-810, doi: 10.1111/j.1365-246x.1996.tb04060.x. [Link]

Rau, R.-J., K.-E. Ching, J.-C. Hu, and J.-C. Lee, 2008: Crustal deformation and block kinematics in transition from collision to subduction: Global positioning system measurements in northern Taiwan, 1995-2005. J. Geophys. Res., 113, doi: 10.1029/2007jb005414. [Link]

Shih, C.-W., 2011: Investigating the basement depth and tectonic evolution in Ilan Plain by seismic reflection method. Master Thesis, National Central University, Taiwan, $120 \mathrm{pp}$.

Sibuet, J.-C., B. Deffontaines, S.-K. Hsu, N. Thareau, J.P. Le Formal, and C.-S. Liu, 1998: Okinawa trough backarc basin: Early tectonic and magmatic evolution. J. Geophys. Res., 103, 30245-30267, doi: 10.1029/98jb01823. [Link]

Steeples, D. W., 2005: Shallow seismic methods. In: Rubin, Y. and S. S. Hubbard (Eds.), Hydrogeophysics, Water Science and Technology Library, Vol. 50, Springer, Dordrecht, 215-251, doi: 10.1007/1-4020-3102-5_8. [Link]

Steeples, D. W. and R. D. Miller, 1998: Avoiding pitfalls in shallow seismic reflection surveys. Geophysics, 63, 1213-1224, doi: 10.1190/1.1444422. [Link] 
Wang, C.-Y., E.-C. Yeh, and S.-R. Song, 2017a: Deep Geothermal Drilling: HCL-1 and HCL-2 boreholes in Ilan. Proceedings 2018 Joint Annual Meeting of the Taiwanese Society of Geology and the Society of Geophysics, Tainan, Taiwan.

Wang, C.-Y., R.-C. Shih, C.-T. Chung, M.-Z. Huang, and H.-Y. Kuo, 2017b: Exploring geothermal structures in the Ilan Plain, Taiwan. Proceedings 19th EGU General Assembly, EGU2017, Vienna, Austria, p. 1870.

Wannamaker, P. E., J. A. Stodt, and L. Rijo, 1987: A stable finite element solution for two-dimensional magnetotelluric modelling. Geophys. J. Int., 88, 277-296, doi: 10.1111/j.1365-246x.1987.tb01380.x. [Link]

Wannamaker, P. E., G. R. Jiracek, J. A. Stodt, T. G. Caldwell, V. M. Gonzalez, J. D. McKnight, and A. D. Porter, 2002: Fluid generation and pathways beneath an active compressional orogen, the New Zealand Southern Alps, inferred from magnetotelluric data. J. Geophys. Res., 107, ETG 6-1-ETG 6-20, doi: 10.1029/2001jb000186. [Link] 